\title{
Influence of growth regulators on yield, quality and preservation of potato stubs in the mountain zone of the Kabardino-Balkaria Republic
}

\author{
Khusen Nazranov, Elena Didanova, Zalim-Geri Shibzukhov*, Maya Orzalieva, and Beslan \\ Nazranov
}

Kabardino-Balkarian State Agrarian University named after V.M. Kokov, st. Ave. Lenina, 1B, 360030 Nalchik, Kabardino-Balkarian Republic, Russia

\begin{abstract}
Plant growth regulators, which helps to activate the initial growth and accelerate the development of plants, stimulate tuber formation, increase the resistance of potatoes to unfavorable soil and climatic conditions, increase the yield and biochemical quality indicators of potato tubers, have great opportunities for increasing potato productivity. Research was carried out on the development of a technological system for regulating the growth and development of potatoes through the complex use of growth regulators in combination with microbiological preparations in the highlands of the KBR. The positive effect of growth regulators on the development of the assimilation surface and root system of potatoes was revealed. Growth regulators have a positive effect on the creation of a pigment background in potato leaves. At the same time, a significant increase in chlorophyll $\mathrm{z}$, chlorophyll $\mathrm{b}$ and carotenoids is observed when using Agrovin Micro Agrovin Mg-Zn-B and is equal to 121.4 , respectively; 46.4 and $46 \mathrm{mg} \%$, up $21.4 ; 23.2$ and $31.0 \%$ above the control variant. The use of PP has a prolonged effect on the growth, development and biochemical composition of potato tubers. The complex use of the drug significantly increases the number, size and weight of tubers, which allows to increase the yield by $30 \%$, improve the biochemical composition of tubers in terms of dry matter and starch content. The use of growth regulators promotes the output of seed fraction tubers by $56 \%$ more than the control variant.
\end{abstract}

\section{Introduction}

Potatoes are one of the main field crops in Russia, which has a significant potential for yield, for the absolute implementation of which it is necessary to use all available reserves of agrotechnical measures. Plant growth regulators possessing great potential for increasing potato productivity have the ability to activate initial growth and accelerate plant development, stimulate tuber formation, increase potato resistance to unfavorable soil and

\footnotetext{
* Corresponding author: konf07@mail.ru
} 
climatic conditions, and increase productivity and biochemical quality indicators of potato tubers.

The range of growth regulators recommended for use on potatoes is very large, but this range does not satisfy the functional capabilities of the growth and development of potatoes in a mountainous zone and an improvement is required in both functional and technological application parameters.

The existing recommendations on the use of growth regulators in potato production technology issued by the Kazan State Agrarian University states that "to increase the profitability of potato production, it is necessary to process the planting material with Zircon $10 \mathrm{ml} / \mathrm{t}$ (working solution consumption $101 / \mathrm{t}$ ) or its mixture with Prestige $(0,751 /$ $\mathrm{t}$ ), or Maxim $(0.41 / \mathrm{t})$, for late varieties of potatoes, the Prestige consumption rate is not less than $11 / \mathrm{t}$. During the period of budding and the beginning of flowering, spray the growing plants with Zircon $10 \mathrm{ml} /$ ha or its mixture with reduced rates of pesticide consumption (by 20-50\%) "[3].

The main task in the development of regulations for the use of growth regulators and their optimization is the problem of finding functional phytoregulators and inducers of plant resistance to diseases and pests, which could stimulate the growth and development of potatoes, increase adaptability to changing conditions of biotic and abiotic factors. It is important to note that great importance is attached to improving the quality indicators of potato tuber and its technological characteristics.

In this regard, it seems very urgent to study the phytoregulatory activity of new biological growth regulators with polyfunctional physiological properties.

The purpose and objectives of the research. The purpose of our scientific research carried out in the mountainous zone of the Kabardino-Balkarian Republic is to substantiate the effect of growth regulators on the productivity, quality and safety of potato tubers, to conduct research to identify the features of the production process of high-quality seed potatoes in a virus-free environment in the mountainous zone of the Kabardino-Balkarian Republic.

Research is carried out to develop scientific recommendations for the use of growth regulators in growing potatoes in the mountainous zone of the Kabardino-Balkarian Republic.

To solve the set goal, you need to solve the following tasks:

1. Conduct research to study the characteristics of the growth and development of the early-maturing variety Zhukovsky early in the experiment;

2. Determine the optimal parameters of the photosynthesizing surface, ensuring the maximum yield of high-quality seed material of the Zhukovsky Early variety;

3. To reveal agrobiological features in the accumulation of the crop, taking into account its structural components;

4. Establish an optimal system for the use of growth regulators in combination with microbiological products.

Research conditions and methods. Research work was carried out in the fields of Zolsky Potato LLC. The enterprise is the main producer of high reproductive potato seed in the region. The soil of the experimental site, where the research was carried out, is leached chernozem and is characterized by the following agrochemical indicators: $\mathrm{pH}$ - 7.1-7.4; humus content according to Tyurin - 5.6\%; easily hydrolyzable nitrogen according to Kornfield $-168 \mathrm{mg} / \mathrm{kg}$; mobile phosphorus according to Chirikov - 22.5 and exchangeable potassium $-85.7 \mathrm{mg} / \mathrm{kg}$.

During field experiments, observations, laboratory analyzes were performed according to generally accepted methods. Phenological observations were carried out in accordance with the "Research Methodology for the Potato Culture" [2]. Analysis of yield data, as well as the grouping of varieties is carried out separately for each digging period. The leaf area 
was calculated using a modified technique for accelerated determination of the leaf area of crops using a scanner. Analysis of the structure of the crop; the resistance of vegetable plants to diseases and pests was assessed before harvesting according to the "Standard scale for taking into account the damage to the surface of tubers by diseases" (Anisimov BV, 2001) [1]. Statistical processing of yield data was carried out using a modified computer program developed in the WINDOWS 2010 environment based on EXEL 7.0.

The cultivation technique in the seed potato breeding nursery relied on the use of advanced technology with the use of high-quality tools and machines. In the studies, for planting, super-elite seed tubers of a domestic variety with an average weight of $65 \mathrm{~g}$ were used. The predecessor in the crop rotation was winter barley. The planting scheme provided for the distribution of 60 thousand tubers per hectare, the planting depth was $10-15 \mathrm{~cm}$, when creating a ridge, its height was $18-20 \mathrm{~cm}$. The working area of the plot is $72 \mathrm{~m} 2$, the accounting area is $60 \mathrm{~m} 2$.

Taking into account a large number of studied physiologically active substances (PAS) and various methods of their use in potatoes, depending on the tasks to be solved, specific schemes for the use of growth regulators and microbiological preparations were laid.

Table 1. Scheme of using growth regulators

\begin{tabular}{|c|l|}
\hline 1. Control & Water \\
\hline 2. Tekamin Max & $\begin{array}{l}\text { Spraying at a plant height of } 15-20 \mathrm{~cm}+\text { in } \\
\text { the budding phase - beginning of flowering } \\
\text { + in the end of flowering phase }\end{array}$ \\
\hline 3. Agrovin Micro $0.51 / \mathrm{t}$ & Spraying tubers before planting \\
\hline $\begin{array}{l}\text { 4. Agrovin Micro } 0.51 / \mathrm{t}+\text { Agrovin Ca } \\
(0.25-1.0 \mathrm{~kg} / \text { ha) }\end{array}$ & $\begin{array}{l}\text { Spraying tubers before planting + Budding } \\
\text { phase }\end{array}$ \\
\hline $\begin{array}{l}\text { 5. Agrovin Micro } 0.51 / \mathrm{t}+\text { Agrovin Mg- } \\
\text { Zn-B }(0,2 ; 0,4 ; 0,6)\end{array}$ & $\begin{array}{l}\text { Spraying tubers before planting + Budding } \\
\text { phase }\end{array}$ \\
\hline
\end{tabular}

Agrovin Mg-Zn-B contains:

- magnesium $\mathrm{Mg} 1.2 \%$

- zinc $\mathrm{Zn} * 0.75 \%$

- boron $\mathrm{B} * 0.2 \%$

Agrovin Ca, Amino acids $22.0 \%$, Ca $8.0 \%$, Boron $-06 \%$.

To activate the soil-forming process, before planting, the fields were treated with an aqueous solution of the microbiological preparation HB-101 at the rate of: - $100 \mathrm{ml}$ HB-101 per 2000 liters of water for an area of 2 hectares. This biological preparation (HB-101) is a non-synthesized, concentrated nutrient solution, which contains elements produced from Japanese cedar, cypress, pine and plantain and used for plant cultivation. The drug is an absolutely natural, highly purified biostimulator of growth and activator of the immune system of plants for all types of cultivated plants, including potatoes, vegetables and fruits. HB-101 supports the plant in the most profound use of its entire internal potential and soil and climatic resources of the environment. A feature of the preparation is that it contains a large amount of flint up to $72 \%$ in a form accessible to plants.

Research results. The research was carried out within the framework of a comprehensive scientific and technical project "Production of high-quality seed potatoes of competitive domestic varieties in a virus-free environment of the mountainous zone of the Kabardino-Balkarian Republic"

The scientific novelty of this work is that for the first time, studies were carried out on the development of a technological system for regulating the growth and development of potatoes through the complex use of growth regulators in combination with microbiological products in the highlands of the KBR. The results were obtained on the effectiveness of the combined use of phytoregulators by processing seed material Agrovin Micro $0.51 / \mathrm{t}$ and 
leaf processing during the growing season of potatoes with Tekamin Max and Agrovin Micro preparations.

One of the main prerequisites for obtaining high potato productivity is its initial growth. Pre-planting treatment of seed material with an organomineral preparation Agrovin Micro $0.51 / t$ showed a positive effect, accelerating the initial growth and development of plants. Hit contributed to an increase in the early and general yield of tubers.

Carrying out morphological studies showed that the use of growth regulators during the growing season stimulated root formation and the laying of a larger number of tubers. To stimulate the initial growth, induction and formation of tubers, Tekamin Max was used at a plant height of $15-20 \mathrm{~cm}$.

Phenological observations revealed an acceleration of the emergence of seedlings, an extension of the reproductive period by 9-12 days in all variants with the use of drugs in comparison with the control. Analyzing the data of biometric observations, it should be noted that growth regulators had a significant formative effect on the habit of potato plants. Growth regulators stimulated the apical growth of potato plants by an average of 2-4 cm compared to the control variant. They contributed to the thickening of the stem diameter by 0.5-0.8 cm in the fifth variant (Table 2). Growth regulators induced root and leaf formation. Processing of seed material Agrovin Micro $(0.51 / \mathrm{t})$ contributed to an increase in root mass by $17 \%$, subsequent processing of the leaf surface (fifth option) increased this indicator by another $7 \%$. The number of planted tubers increases by 5-7 pcs / bush.

Table 2. Influence of growth regulators on biometric indicators of potato plants (flowering phase), 2019-2020

\begin{tabular}{|c|c|c|c|c|}
\hline \multirow{2}{*}{$\begin{array}{l}\text { Experimental } \\
\text { variants }\end{array}$} & \multirow{2}{*}{$\begin{array}{c}\text { Plant height, } \\
\mathrm{cm}\end{array}$} & \multirow{2}{*}{$\begin{array}{l}\text { Leaf surface } \\
\text { area, } \mathrm{m} 2\end{array}$} & \multicolumn{2}{|c|}{ Wet weight of plant parts, $g$} \\
\hline & & & $\begin{array}{l}\text { The mass of } \\
\text { the tops of the } \\
\text { bush }\end{array}$ & Root system \\
\hline 1.Control & 49,4 & 0,38 & 294 & 28,4 \\
\hline 2.Tekamin Max & 56,5 & 0,47 & 358 & 30,7 \\
\hline $\begin{array}{l}\text { 3.Agrovin Micro } \\
0.51 / \mathrm{t}\end{array}$ & 57,1 & 0,51 & 364 & 33,4 \\
\hline $\begin{array}{l}\text { 4.Agrovin Micro } \\
0.51 / \mathrm{t}+\text { Agrovin } \\
\mathrm{Ca}(0.25-1.0 \mathrm{~kg} / \\
\mathrm{ha})\end{array}$ & 60,4 & 0,62 & 396 & 34,1 \\
\hline $\begin{array}{l}\text { 5. Agrovin Micro } \\
0.51 / \mathrm{t}+\text { Agrovin } \\
\mathrm{Mg}-\mathrm{Zn}-\mathrm{B} \quad(0.2 ; \\
0.4 ; 0.6)\end{array}$ & 62,7 & 0,63 & 415 & 35,7 \\
\hline
\end{tabular}

Treatment of potatoes during the growing season contributes to an increase in the linear growth of potato plants of the Zhukovsky Early variety by an average of $14.4 \%$, the mass of tops from one bush in the fifth variant exceeded the control variant by $29.4 \%$.In the course of experimental studies, the content of chlorophyll $\mathrm{z}$, chlorophyll $\mathrm{b}$ and carotenoids in potato leaves. It has been proved that growth regulators have a positive effect on the creation of a pigment background in potato leaves. At the same time, a significant increase in chlorophyll $\mathrm{z}$, chlorophyll $\mathrm{b}$ and carotenoids is observed when using Agrovin Micro Agrovin Mg-Zn-B and is equal to 121.4, respectively; 46.4 and $46 \mathrm{mg} \%$, up 21.4; 23.2 and $31.0 \%$ above the control variant. The use of PP has a prolonged effect on the growth, development and biochemical composition of potato tubers.

The high content of chlorophyll in the leaves of potato plants grown with the use of growth regulators is due to the rejuvenating effect and the ability of growth regulators to 
stimulate the resistance of the protein-chlorophyll complex to growth and development conditions [4].

An integral indicator of the effectiveness of the use of growth regulators in the production of seed material of the highest reproduction of potatoes is the yield. In this regard, the analysis of the results of scientific research in their independent and complex application is of considerable interest.

Analysis of the data in Table 3 shows that the use of Tekamin Max by three spraying during the growing season gives an increase in yield by an average of $18.9 \%$.

Treatment of tubers three days before planting Agrovin Micro $0.51 / \mathrm{t}$ allows increasing crop productivity by an average of $19 \%$.

Similar results were obtained in the studies of OG Korneva, who writes that "the use of growth regulators for pre-planting treatment of tubers and three-time spraying of vegetative plants; gives an increase in the aboveground mass of plants by $24-33 \%$, leaf area - by 18 $21 \%$ "[5].

At the same time, with the complex use of Agrovin Micro $0.51 / \mathrm{t}+$ Agrovin $\mathrm{Mg}-\mathrm{Zn}-\mathrm{B}$ in the fifth variant, it is possible to increase the yield by more than $30 \%$ compared to the control variant.

The same data were obtained in the studies of Petryakov. According to the results of his research, he writes that "the complex use of vermicompost and growth regulators contributed to the most stable and high growth of potato productivity in all the years of research". The maximum yield increase in the Zhukovsky Early variety was noted in the complex version with Zircon and amounted to $8.1 \mathrm{t} /$ ha or $34.5 \%$, in the Sante variety in the complex version with Extrasol $-10.7 \mathrm{t} /$ ha or $36.0 \%$. The use of vermicompost was accompanied by the yield of tubers in the varieties Zhukovsky early and Sante, respectively, by $22.6 \%$ and $26.3 \%$. Growth regulators caused an increase in yield in the Zhukovsky Early variety by $8.5-15.7 \%$, in Sante $-7.1-12.1 \%$. In the complex variant with Extrasol, an increase in the yield of tubers in the Zhukovsky Early variety by $2.4 \%$ was observed. at Sante - by $3.3 \%$ "[6].

Table 3. Yield of the early-ripening variety Zhukovsky early under the conditions of using growth regulators

\begin{tabular}{|l|c|c|c|}
\hline \multirow{2}{*}{ Experiment options } & \multicolumn{3}{|c|}{ Yield, $\mathrm{t} / \mathrm{ha}$} \\
\cline { 2 - 4 } & 2019 & 2020 & Medium \\
\hline 1. Control & 16,4 & 15,1 & 15,8 \\
\hline 2.Tekamin Max & 18,2 & 19,3 & 19,4 \\
\hline $\begin{array}{c}\text { 3.Agrovin Micro 0.5 1/ } \\
\mathrm{t}\end{array}$ & 18,9 & 19,8 & 22,0 \\
\hline $\begin{array}{l}\text { 4.Agrovin Micro 0.5 1/ } \\
\mathrm{t}+\text { Agrovin Ca (0.25 - } \\
\text { 1.0 kg / ha) }\end{array}$ & 21,4 & 22,5 & \\
\hline $\begin{array}{l}\text { 5. Agrovin Micro 0.5 1/ } \\
\mathrm{t}+\text { Agrovin Mg-Zn-B } \\
(0.2 ; 0.4 ; 0.6)\end{array}$ & 22,7 & & 22,9 \\
\hline NSR05 & & 23,1 & \\
\hline
\end{tabular}

It should be noted that the increase in yield was provided, first of all, due to an increase in the number of tubers and their average mass.

The use of bioregulators of growth in the production technology of potato tubers has a significant effect on the quality indicators of the crop. So, Aliev S.G., Wildflush I.R., Mikkelson, R.L. according to the results of their research, they cite data that "under the influence of Ecosil, in comparison with the background N100P60K130, the starch content increased by $0.7 \%$, the Basfoliar 36 extra - by $1.0 \%$, and the starch yield - by 3.5 and $6.5 \mathrm{c} /$ ha respectively. Under the influence of Vitamar, the starch content increased by $1.5 \%$, and 
the starch yield increased by $7.4 \mathrm{c} /$ ha. The combined treatment with these preparations increased the starch content in tubers in comparison with the background variant by $1.4 \%$, and the starch yield - by $9.6 \mathrm{c} /$ ha ", the same results were obtained by many researchers, which confirms the effectiveness of growth regulators to improve the biochemical parameters of tubers. potatoes $[7,8,9,10,11,12]$.

To characterize the quality of the products obtained when using growth regulators, biochemical studies of tubers were carried out. The analysis of these data showed that the use of drugs stimulated the accumulation of dry substances in potato tubers, on average, this indicator in the fifth variant is higher than the control one by $1.5-1.8 \%$. The starch content exceeded the control variant by $1-1.2 \%$, respectively.

Output. The positive effect of growth regulators on the development of the leaf surface area and the mass of the potato root system was revealed. The use of biological growth regulators has a prolonged effect on the growth processes of plants, on the development and biochemical parameters of potato tubers. Complex use of the drug Agrovin Micro $0.51 / \mathrm{t}+$ Agrovin Mg-Zn-B $(0.2 ; 0.4 ; 0.6)$ significantly increases the number, size and weight of tubers, which makes it possible to increase the yield by $30 \%$, improve the biochemical composition tubers in terms of dry matter and starch content. The use of growth regulators promotes the output of seed fraction tubers by $56 \%$ more than the control variant.

\section{References}

1. B.V. Anisimov, Varietal resources and quality of seed potatoes, 108 (2001)

2. B.A. Dospekhov, Field experiment technique, 351 (1985)

3. V.P. Vladimirov, Recommendations for the use of b. Growth regulators in potato growing technology, 50 (2015)

4. G.L. Matevosyan, XIII International Plant Protiction Congress The Hague, The Netherlands, 654 (1995)

5. O.G. Kornev, N.K. Dubrovin, Collection of scientific papers on vegetable growing and melon growing, To the 110th anniversary of the birth of Boris Vasilyevich Kvasnikov, 232 (2009)

6. A.S. Petrukhin, Ways of innovative development of the economy of the Ryazan region: collection of articles of the third regional conference young scientists, 94 (2015)

7. S.G. Aliev, I.R. Wildflush, Belarusian GSA, Soil science and agrochemistry, 1(46) (2011)

8. R.L. Mikkelson, Better Crops, 89, 6 (2005)

9. S.V. Murashev, S.D. Kiru, V.G. Verzhuk, A.V. Pavlov, Agronomy Research, 18(2), $494(2020)$

10. I.P. Uromova, A.V. Kozlov, N.N. Koposova, Y.M. Avdeev, A.A. Tesalovs, International Journal of Innovative Technology and Exploring Engineering, 8(7), 756 (2019)

11. M. Głosek-Sobieraj, B. Cwalina-Ambroziak, K. Hamouz, Gesunde Pflanzen, 70(1) (2018)

12. I.P. Uromova, N.N. Koposova, A.V. Kozlov, D.A. Shtyrlin, Y.Y. Davydova, Biosciences Biotechnology Research Asia, 13(1), 561 (2016) 